\title{
Impactos de la Práctica de la Teología India entre los Mazatecos de Oaxaca
}

\author{
Alicia M. Barabas \\ Centro INAH Oaxaca, Oaxaca, México \\ E-mail: barbar2@prodigy.net.mx
}




\section{Resumen}

El artículo constituye una primera aproximación al estudio de los impactos producidos por la praxis misional de la iglesia católica conocida como Teología India en la cosmología y la praxis ritual de los mazatecos, uno de los pueblos indígenas del Estado de Oaxaca, en México. Después de un breve panorama de esta corriente de nueva evangelización misional se analizan los sincretismos e innovaciones inducidos por los misioneros de la Orden de los Josefinos y los catequistas mazatecos preparados por ellos para, finalmente, ubicar esta práctica misional dentro de los procesos de aculturación dirigida.

Palabras clave: Mazatecos de Oaxaca. Teología India. Cambio Religioso Dirigido.
Abstract

This paper analyses missional practices (especially those of catholic Teologia India) impact in mazatecos (indigenous people from Oaxaca, Mexico) cosmology and ritual activity. We describe this evangelic religious line to be able to analise sincretisms and inovations introduced by missionaires from Orden de los Josefinos and by native catequists trained by them. We think about these practices as processes of oriented acculturation.

Keywords: Mazatecos from Oaxaca. Teologia India. Oriented Religious Transformation 


\section{Introducion}

耳 stas páginas constituyen una primera aproximación al estudio de los impactos producidos por la praxis misional de la iglesia católica conocida como Teología India en algunos de los pueblos indígenas del estado de Oaxaca, en México; en este caso el pueblo mazateco. Ya en la Summer School of Religions de San Giminniano, en 2009, pusimos en evidencia el racismo implícito -o a veces explícito- en la práctica de la Iglesia católica y de otras religiones, la discriminación hacia el Otro que tiene una religión y una cultura diferentes, a las cuales, en un acto de hegemonía, se pretende erradicar o, como en este caso, transformar hasta el punto de descaracterizarlas en pro de la evangelización católica. Esta actitud contemporánea de la Iglesia hace pensar que en su ideología acerca de los pueblos indígenas aún subyace el concepto de bárbaro, que alberga un conjunto de representaciones minusvaloradoras que el observador se forma sobre Otro diferente, con mayor o menor independencia de las características de lo observado. Como proceso, las imágenes sobre el bárbaro se construyen entrelazadas con la historia y los contextos, y sus variaciones de fondo y de forma se relacionan directamente con las ideologías imperantes en diferentes épocas, aunque todas tienen en común un punto de partida etnocéntrico: el bárbaro es un Otro percibido como diferente a partir del que observa y relata, es el opuesto a un 'nosotros' colocado en la posición de superioridad y hegemonía.

En América los prejuicios inferiorizadores trasplantados desde Europa y adheridos a la imagen del Otro-indio, así como los construidos con posterioridad, han contribuido a la cristalización de un imaginario racista, que hasta ahora desafía cualquier intento global 
de transformación de las relaciones apelando al respeto a la pluralidad cultural. La existencia actual de múltiples preconceptos y comportamientos discriminatorios hace sospechar que el imaginario del indio como bárbaro no ha desaparecido, sino que constituye un componente estructural del racismo.

El bárbaro imaginado en el medioevo cristiano, que más tarde llegaría a América, incluía un acervo de estereotipos negativos, causales de desprecio e inferiorización. Pero a los ojos de la mayoría de los cronistas y de los frailes, los indios tenían sus propios grandes estigmas: idolatría, paganismo, sacrificio humano, canibalismo, brujería, poligamia, incesto, sodomía. Un atributo clave para la construcción del imaginario desacreditador sobre los indios fue - sigue siendo la brujería, asociada a la idolatría y el paganismo, como conjunto de creencias y prácticas religiosas prohibidas y al servicio del demonio. (Barabas, 2000)

Generalmente lo que se desacreditaba como barbarie, y se perseguía y castigaba cruelmente, eran los rituales y discursos de rebelión y las expresiones de cultura contestataria. En Oaxaca se llevaron a cabo procesos inquisitoriales en 1544-1546 contra los caciques de Yanhuitlán en la Mixteca Alta, acusados de idolatría y bigamia (Sepúlveda, 1999). Igualmente, se conocen los Autos Criminales contra indígenas zapotecos rebeldes de la Sierra Norte, en 1667-68, 1700 y 1736, por hacer ritos en el monte y las cuevas (Gillow, 1978, De la Fuente, 1939). Berlín (1988) reproduce acusaciones de idolatría hechas a los indios zapotecos principales y macehuales de Sola de Vega, Loxicha y Zimatlán, en la Sierra Sur, entre 1634 y 1655, por realizar sortilegios, leer libros demoníacos, y hacer ritos y sacrificios al demonio o los dioses de su gentilidad. La persistencia de la religión propia fundada en las poderosas entidades extrahumanas territoriales, conocidas como Dueños del Lugar, que moran en los cerros y otros puntos de los etnoterritorios, y el uso de drogas alucinógenas para comunicarse con ellos, provocaban horror a los colonizadores y los sacerdotes, y eran considerados obras de Satanás.

En la actualidad persisten fragmentos significativos de aquel imaginario colonial y de la ideología de la desigualdad de la diferencia 
que lo sustentaba, muchas veces subyacentes y racionalizados pero igualmente activos en la construcción contemporánea de la alteridad. El imaginario sobre el bárbaro no ha desaparecido sino que sobrevive implícito en las representaciones comunes de la sociedad y en la ideología y práctica de la iglesia.

\section{Las Nuevas Opciones del Catolicismo}

Durante el Concilio Vaticano II (1963-65) la iglesia advirtió la fragilidad del catolicismo y el avance del protestantismo en América Latina y señaló la urgencia de un nuevo enfoque teológico para la evangelización, más respetuoso del "catolicismo indígena". Este cambio ideológico dio impulso a reuniones eclesiásticas en las que se discutieron y organizaron nuevas formas de pastoral misionera, que se concretizaron en las comunidades eclesiales de base (CEB). Las diversas reuniones adquirieron un tono radical en favor de los indígenas y polémico hacia las posturas conservadoras de la iglesia oficial, como puede advertirse en los documentos de las reuniones de Iquitos, 1971; Asunción, 1972; Curitiba, 1973-1974; Manaus I, 1977; Puebla, 1979; Manaus II, 1980; Brasilia, 1983 y Bogotá, 1985 (J. Botasso, recop., 1986).

Los postulados de la conocida como Teología de la Liberación, que se consolidaron durante esos años, quedaron claros en el Documento producido por los Obispos en Bogotá (1985). En él se manifestaban en favor del respeto a las culturas e identidades indígenas y del apoyo a la creación de 'iglesias autóctonas'; con sus propias teologías, liturgias, jerarquías y formas de organización adecuadas a las singularidades culturales de los grupos. Postulaban la evangelización integral de los indígenas y la preparación de evangelizadores autóctonos, se pronunciaban por el compromiso de los misioneros en la defensa de las tierras, los derechos humanos y la autodeterminación de los pueblos indígenas, y denunciaban los propósitos etnocidas de las políticas indigenistas y las legislaciones nacionales (Centro Episcopal Latinoamericano, CELAM, 1986, pp.17-22). Durante esta época el compromiso político y la intención de respeto cultural para la evangelización fueron asumidos por las CEB (por ejemplo, en el CIMI, en Brasil, en el Equipo 
Nacional de Misiones de la Conferencia Episcopal Paraguaya, en las Comunidades Cristianas en Perú) (M. Marzal, 1989) y muchos otros grupos eclesiales en distintos países latinoamericanos. La corriente transformadora de la iglesia respaldaba a las nacientes organizaciones etnopolíticas, apoyando la promoción de encuentros indígenas locales, nacionales e internacionales, cursos de capacitación para líderes y promotores, comisiones de estudio para demarcaciones territoriales, para derechos humanos y muchas otras. Es posible que en estas décadas la iglesia haya tenido mayor injerencia entre los grupos indígenas, campesinos y clases populares urbanas que en los últimos dos siglos.

Entre los estudios antropológicos que analizan el estilo de religiosidad que se está gestando en los indígenas bajo la influencia de la nueva teología, el de Marzal (1989) realizado entre los migrantes a la ciudad de Lima, es optimista en cuanto a la articulación respetuosa de creencias tradicionales en el nuevo sincretismo que se configura con la formación de las comunidades cristianas y su preocupación por la espiritualidad fraternal. Otro caso significativo donde se advierte la influencia de la neocorriente católica en las creencias y la vida de los tzeltales, lo describe X. Leyva (1995) para la migración colonizadora de indígenas de los Altos de Chiapas hacia la selva lacandona que tuvo lugar en la década de 1970, ideológicamente guiada por catequistas mayas de las CEB, quienes enseñaban el Evangelio de San Lucas acerca de la libertad de los oprimidos y el Libro del Éxodo, traducido al tzeltal, sobre la migración de los pobres hacia una tierra de prosperidad. El Libro era leído en las comunidades y los catequistas indios escribían adaptaciones que pasaban a integrar las lecciones de catecismo llamadas "estamos buscando la libertad", en las que se hablaba del "éxodo hacia la tierra prometida en la que construirían una vida mejor".

Muchos sectores sociales consideran positivamente la renovación que la Teología de la Liberación ha impuesto a la institución eclesiástica. Incluso los indígenas reconocen la transformación operada en este sector de la iglesia, pero aún le señalan el neopaternalismo, la retórica más que la práctica respetuosa de las diferencias culturales y la poca atención prestada a los problemas étnicos; críticas formuladas por las organizaciones indígenas y los agentes indígenas de la Pastoral reunidos en Consultas Ecuménicas en 1983 (Brasilia) y 1986 (Quito). 
Es posible que la efervescencia pastoral y la práctica política de los misioneros atemorizaran a la iglesia. Por una parte, la aceptación de las diversas manifestaciones culturales de Dios y el fomento de iglesias y religiosos indígenas, ponían en cuestión la unidad y hegemonía de la iglesia oficial y legitimaban los temidos catolicismos populares que durante siglos habían sido catalogados como paganismos e idolatrías. Por otra parte, el compromiso y la participación eclesial en las luchas de los pobres daban a la nueva pastoral indígena un matiz marxista demasiado radical para la iglesia oficial. Hacia 1984 el Vaticano se pronunció contra la Teología de la Liberación considerándola un peligro fundamental para la fe de la iglesia y desde entonces fueron cuestionados algunos teólogos en América latina y Europa. No obstante, entre 1999 y 2003, los miembros de la presidencia del CELAM fueron recibidos por el Cardenal Ratzinger en Roma, donde les pidió promover diálogos teológicos entre obispos y promotores de la Teología India con el fin de valorar sus aportes y clarificar ciertos puntos en discusión, volviendo a expresar su interés por carta al Presidente de CELAM en 2004.

\section{La Teología India}

Hacia 1990 se dio a conocer oficialmente la consolidación de una corriente dentro de la Teología de la Liberación, conocida como Teología India, más directamente orientada hacia la inculturación religiosa y la construcción de iglesias autóctonas, cuyos principios fueron expresados en el I Taller Latinoamericano de Teología India realizado en México en 1991 con el auspicio de CELAM. Sin embargo sus orígenes en México se remontan a los alrededores de 1974 en la Diócesis de San Cristóbal de Las Casas, en Chiapas, bajo la gestión del Obispo Don Samuel Ruíz, muy inspirado por la declaración de Barbados (1970). Desde entonces se han realizado numerosos encuentros regionales, nacionales y latinoamericanos en los que dan cuenta de los avances en la inculturación del Evangelio en los pueblos indígenas, mediante la realización de experiencias piloto de inculturación de la liturgia, formación de agentes de pastoral indígena y sacerdotes indígenas. Hacia 2006, después de la celebración del III Simposio de 
Teología India en Guatemala, el CELAM resaltaba algunos logros y desafíos. Entre los primeros, haber consensuado que la Teología India es una verdadera teología aunque trabaja con otra metodología que la teología clásica occidental, valiéndose de mitos, ritos, tradiciones y sueños de las culturas indígenas como datos para la inculturación. Entre los segundos, la pregunta acerca de si las vivencias religiosas de los indígenas son vestigios de sus creencias antiguas o son fruto de la evangelización fundante.

¿Pero de qué se trata la inculturación? De acuerdo con las ideas expresadas en el Concilio Vaticano II es la acción de la Iglesia para encarnar el Evangelio en las distintas culturas y, al mismo tiempo, trasmitir a aquéllas sus valores asumiendo lo que hay de bueno en ellas y renovándolas desde el interior. Es decir que desde su formulación queda clara la idea de que la inculturación pretende promover una nueva forma de evangelización en pueblos con culturas diferentes para purificar los contenidos y expresiones de las religiones de esos pueblos y transformarlas desde el interior adaptándolas a los valores del cristianismo; esto es, convertir la cultura local al Evangelio. Tal vez en algún momento la antropología pudo pensar que esta práctica de la Iglesia era más respetuosa de las culturas nativas, sin embargo la experiencia con los mazatecos me obliga a reconsiderar que se trata de la misma empresa etnocida de la evangelización católica, pero con estrategias más sutiles, aparentemente participativas y pluralistas, y por ello mucho más perversa.

Cuturi (2008, p. 20) en su panorámica de la misionalización durante los siglos coloniales señala que a la iglesia se le hizo evidente que la práctica misionera debía diversificarse según la "naturaleza" de las poblaciones a evangelizar y se debían "conservar" aspectos de la cultura considerados positivos y sobre éstos edificar el proyecto evangelizador, y por otra parte, suprimir los negativos. En base a la existencia y compatibilidad de las "buenas leyes" con el Evangelio y la necesidad de hacer accesible el mensaje cristiano, se articuló la idea y la praxis, desde el siglo XVI en adelante, del "acomodamiento", denominado por el Concilio Vaticano II como "adaptación" y en época más reciente incluida en la noción de "inculturación". En el caso shuar y ashuar tratado por Gnerre (2008), el tipo de adaptación 
fue desde la modificación total implementada en los internados para niños hacia una adaptación penetrante, orientada al moldeamiento del mensaje evangélico a favor de una liturgia indígena empapada de las convenciones comunicativas, cosmogónicas y de identidad shuar y ashuar, por lo cual fue bien aceptada por los indígenas. Agrega Cuturi (2008, p. 26) que este cambio de perspectiva tuvo lugar después del Concilio Vaticano II y del decreto Ad gentes (1966) dedicado a la actividad misionera y a la fundación de iglesias particulares o locales. En la acción cotidiana de los misioneros esta propuesta se traducía en la inserción y mimetización con la población indígena para introducir el mensaje evangelizador y en un delicado trabajo sincrético basado en la interpretación de los mitos locales leídos a la luz de los aspectos fundamentales del cristianismo. La política de traducción del mensaje evangélico fue atribuyendo cada vez mayor importancia a la interpretación teológica de la religiosidad de los nativos.

En el caso que trataré no sólo existe la búsqueda de inserción en la comunidad por parte de misioneros foráneos sino principalmente por parte de misioneros, catequistas y promotores de base reclutados entre los mismos indígenas. Es decir que, como señalan diversos autores (Cuturi, 2008, p. 37), los sujetos a convertir están activamente implicados en retraducir y transformar el cristianismo impuesto para reconstruir su propia identidad étnica y cultural. En esta nueva fase de la inculturación, como señalaba Don Samuel Ruíz (1993, p. 23), se fue pasando de una "pastoral indigenista" (en manos de agentes extraños a las comunidades indígenas), a una "pastoral indígena" (en manos de agentes de las propias comunidades). Sin embargo estos agentes de la pastoral indígena, dirigidos por los sacerdotes católicos, son indígenas ya afiliados a las filas del catolicismo que buscan transformar y suavizar la práctica religiosa y las creencias de sus paisanos.

Si en forma sucinta entendemos la aculturación como el proceso de cambios mediante la adopción de la cultura ajena y el renunciamiento de la propia, la inculturación de la Teología India sería el punto culminante de la aculturación religiosa, en la cual se induce a la población indígena a aceptar los sincretismos de forma y de fondo entre la religión propia y el catolicismo de la nueva pastoral evangelizadora. 
La pregunta que uno se formula ante el largo proceso de la iglesia hacia la actual metodología de inculturación es, qué aspectos de la cultura indígena se eligen o se excluyen para armonizarlos con el mensaje evangélico y en particular, quiénes realizan esa elección. Sobre el primer asunto volveré más tarde a través de la exposición de algunos ejemplos en la región indígena Mazateca de Oaxaca.

Si retomamos el ya conocido concepto de control cultural (Bonfil, $1981)^{1}$ observamos la gran diferencia que existe entre que este proceso de inculturación sea dirigido y realizado por la iglesia o por los propios usuarios de la cultura. Podrá argumentarse que, para ser efectiva y construirse como iglesia autóctona, la inculturación requiere de actitudes participativas y en alguna forma consensuadas por los indígenas, pero bien sabemos que los procesos participativos pueden ser manipulados y dirigidos, en especial cuando los catequistas y grupos eclesiales de base están formados por indígenas educados por la Iglesia católica que son intermediarios entre ella y sus paisanos. Pero por sobre todo debe enfatizarse que, aunque las nuevas ideas religiosas y la nueva liturgia sean aceptadas y practicadas, este proceso no resulta del proyecto creativo y de la agencia del colectivo indígena que se apropia de la cultura ajena sino del proyecto y de la agencia de los misioneros de la Teología India.

A pesar de ser la opción considerada como más progresista y respetuosa de las culturas indígenas, la Teología India, en el caso que trataré enseguida, se nos presenta -al igual que la iglesia oficial-como una empresa etnocida que aún considera a los indios como paganos e idólatras, por lo tanto inferiores, que deben ser civilizados y redimidos transformando su religión y ritualidad en algo nuevo, lo más parecido posible a la religión y liturgia católicas.

\section{La Teología India en la Región Mazateca de Oaxaca}

En Oaxaca, la Teología India parece menos inclinada hacia la condición material de los fieles y más hacia su condición y características culturales y religiosas. En palabras de uno de sus miembros:

[...] la Teología de la Liberación sólo le hace conciencia al pueblo de sus condiciones de opresión pero no respeta 
la teología que ya está en los pueblos indígenas, piensan que la teología sólo viene de Europa, que aquí la gente tiene creencias pero medio chuecas, creen en Dios pero no en el Dios verdadero. (H. Prado, Huautla de Jiménez)

Ante esta perspectiva de la iglesia progresista, los sacerdotes y catequistas de la Teología India intentan construir una 'iglesia autóctona' reelaborando la cosmovisión y ritualidad indígena en términos del catolicismo.

En Oaxaca, la propuesta de una línea más pastoral (de campo) y menos académica surgió hacia fines de la década de 1970 en el Seminario Interregional del Sureste (SEDESURE), que comprendía las diócesis de Oaxaca y Chiapas, comprometido con la Teología de la Liberación. La gran concurrencia indígena en el Seminario orientó la discusión hacia la Teología India y hacia la demanda de una "iglesia más indígena", lo que encontró eco en la Prelatura Mazateca.

El proceso de "inculturación"2 que aquí trato comenzó entonces hacia 1970 cuando algunos sacerdotes de la orden misionera de los Josefinos, activos en la Teología India, llegaron a la sierra mazateca encontrando que los feligreses estaban muy poco atendidos por la Arquidiócesis de Oaxaca, no se realizaba pastoral, las visitas sacerdotales eran a veces anuales y los feligreses sólo memorizaban las oraciones en español sin comprender su contenido. Los Josefinos comenzaron a evangelizar a los mazatecos visitando cada comunidad durante diez días y "enseñando la palabra de Dios" acompañada de cantos en mazateco hasta que compusieron un nuevo esquema de misa con diez cantos. El propósito era “la recuperación de la religión mazateca y la formación de una iglesia autóctona desde los esquemas mentales locales y no desde los occidentales, para desarrollar una nueva religión indígena".

Los misioneros Josefinos han sido activos en CENAMI (Centro Nacional para las Misiones Indígenas), institución creada por varios obispos de México pertenecientes a la Teología de la Libración. No sin disputas intrarreligiosas con los diocesanos, los Josefinos consiguieron desarrollar una pastoral indígena en la Prelatura Mazateca (Huautla, Ayautla, Tenango, Mazatlán, Chilchotla, Huehuetlán y otros municipios) con el apoyo de CENAMI que diseñó el plan de la pastoral. Desde 
1986 los sacerdotes locales organizaban cursos y talleres, llamados “misiones", en los que participaban caracterizados del pueblo, autoridades municipales y jóvenes, algunos seleccionados para ser catequistas y promotores de los grupos eclesiales de base, la mayor parte de ellos mazatecos muy apegados a la Iglesia y con educación eclesiástica previa o recibida durante este proceso pastoral, que eran elegidos por el sacerdote o por la comunidad para ser líderes de misionalización. En 1992 el éxito de esta práctica se consumó con la creación de la Escuela de Ministerios Indígenas que intentaba rescatar, estudiar y defender la existencia de una religión mazateca inculturada.

En tanto que los catequistas se orientaban al trabajo propiamente pastoral en el espacio de la parroquia, los grupos de base eran mucho más activos en cada comunidad, visitando a las familias en sus domicilios y promoviendo asambleas barriales quincenales o mensuales en las que combinaban la acción pastoral con la discusión de los problemas locales. Estos Talleres reunían gente de diversas comunidades ( 100 a 150 personas) y solían durar una semana, durante la cual se les hablaba de historia prehispánica nahuatl y los mazatecos asistentes contestaban "si se creía lo mismo entre los mazatecos o cuáles eran las diferencias". Principalmente se leía la Biblia y, mediante el mismo procedimiento de la comparación, se discutía con los mazatecos asistentes, muchos de ellos chjota chine (chamanes). En los talleres, los agentes de la pastoral inculturaban el Evangelio en la religión mazateca buscando semejanzas, coincidencias y diferencias entre las Sagradas Escrituras y la cosmovisión y ritualidad indígenas, para lo cual les formulaban preguntas sobre "sus valores, sus mitos, sus creencias, sus leyendas, sus ritos, sus sueños", que eran respondidas por los chjota chine y los caracterizados. En la siguiente reunión los misioneros escribían las respuestas consensuadas e "interpretaban" y "adecuaban" la cosmovisión mazateca a la religión católica para "ir transformando el culto".

Uno de los resultados de esta intensa práctica llevada a cabo por espacio de ocho años (hasta el 2000), fue la escritura del libro Elementos Rituales Mazatecos (1998), que compendia las creencias y prácticas rituales de la "nueva espiritualidad mazateca", como los Josefinos llaman 
a este sincretismo inducido, que fue entregado y leído en asamblea en todas las comunidades. Otro, tal vez más grave, fue la inculturación del evangelio en las matrices de la religión mazateca y el minucioso proselitismo de la "nueva espiritualidad mazateca" hecho en cada unidad doméstica, en la que por lo común vive un chamán, ya que la mazateca es una sociedad chamánica. De hecho el padre Sánchez se vanagloria de que muchos de los actuales chjota chjine fueron participantes en los Talleres y de que mucha gente volvió a practicar rituales pero dentro de la iglesia.

En cuanto al citado libro escrito por los Josefinos en español, que está siendo traducido al mazateco, en la Presentación señalan que el material editado fue elaborado con el aporte de los catequistas y promotores de la fe de la Prelatura de Huautla, que participan en la Escuela de Ministerios Indígenas, con la colaboración de los Grupos de Base de la Parroquia de Huautla. Indican que, partiendo de la premisa de que:

Dios se manifiesta en todas las culturas y religiones para llevar su designio salvador, el material quiere suscitar la reflexión teológico-filosófica mazateca a fin de ir dando pasos hacia la inculturación del Evangelio y de la Iglesia y llegar algún día a construir una verdadera Iglesia Autóctona, que lleve a los indígenas un mensaje de salvación desde su propios valores, leídos a la luz del Evangelio de Jesucristo (J. L. Sánchez, Huautla de Jiménez).

Sin embargo, en este caso no se trata de una "relectura del cristianismo hecha desde la cultura mazateca", como dice el sacerdote Josefino, sino de la relectura de la religión y ritualidad de la colectividad mazateca hecha por los Josefinos y los catequistas bajo los principios del cristianismo, sistematizada en un libro y en numerosos nuevos rituales, e imbuida a los chamanes de cada familia en sucesivos actos de proselitismo como un nuevo cuerpo de creencias, que hoy se encuentra diseminado por los pueblos como la nueva cosmovisión mazateca. Tal como afirma Colajanni (2008), los misioneros son reformadores y agentes del cambio cultural. 


\section{Las Transformaciones de la Cosmología Mazateca Inducidas por los Misioneros}

Los cambios en la cosmología y la ritualidad mazatecas están íntimamente relacionados, y es por ello que las transformaciones inducidas en una afectan necesariamente la otra. En esta sección quiero presentar algunas de las transformaciones que surgen de la adecuación hecha por los diferentes agentes de la Pastoral, tal como se observan en el libro escrito por la Prelatura de Huautla. En comparación, y a fin de observar los cambios, me valdré de las etnografías antropológicas más relevantes realizadas con anterioridad a esta nueva evangelización (Incháustegui) y contemporánea (Boege) o posteriormente a ella (Manrique, 2004, 2008). Es así que cuando escribo cosmología o ritualidad tradicionales me refiero a las concepciones y prácticas que primaban antes de 1980, ya sincretizadas secularmente con el catolicismo oficial, en tanto que la nueva cosmovisión y ritualidad se observan etnográficamente con posterioridad a 1980 y en relación con la práctica de inculturación de la Teología India.

\section{Algunas Transformaciones Inducidas en la Cosmología y en las Creencias}

a) La cosmología del grupo, ya permeada por el catolicismo, ha sido registrada en las clásicas etnografías de Inchaustegui, (1977, 1994), quien trabajó en la región desde 1954. En aquellos años los shutá shiné (chamanes) dirigían los complejos rituales terapéuticos y, aunque la gente sabía que tanto podían ser benéficos como maléficos, el etnógrafo notaba que progresivamente los "Dueños de la tierra, los cerros y las aguas se convierten en seres puramente malvados, y múltiples advocaciones del diablo". Tanto Inchaústegui como Boege (1988), al referirse al supramundo, mencionan la existencia de una mesa sagrada de plata en el cielo, en la que vive y mora el Padre Eterno (no se menciona a una Madre Eterna), ubicada en el oriente, en el lugar más sagrado o do asean. Estos autores registraron numerosos relatos entre los que predomina el ciclo de los gemelos Sol y Luna y los relatos de los animales dadores de bienes a los hombres. 
Manrique (2008), quien realizó trabajo etnográfico desde 1996 entrevistando chjota chjine de diferentes pueblos, encontró ya muy difundida entre los especialistas una versión muy detallada y organizada de la cosmovisión mazateca, que concuerda en muchos aspectos con la registrada en el libro Elementos Rituales Mazatecos.

En esta nueva cosmovisión, el supramundo o espacio celeste se presenta subdividido. El plano superior está conformado por trece cielos o pisos, a manera de peldaños, formando un arco que inicia en el oriente y concluye en el poniente. En cada piso existe una Mesa atendida por una pareja sagrada; los primeros sabios (chamanes), considerados como ancestros comunes de la etnia. En la séptima Mesa se encuentran el Padre y la Madre Dios, N'ai na niná, que es la pareja más importante por ser considerados como los Padres eternos creadores del mundo. En el extremo oriental del mundo está el do asean, el lugar más sagrado, ubicado entre el inicio del arco celeste y el final del arco del inframundo. En este espacio los mazatecos creen que radican el Padre-Madre eterno o Dios creador del Universo, el Padre-Madre Dios, Jesucristo y otras deidades benéficas. Para algunos el Padre Sol es el mismo Dios Padre, Jesucristo y la Santísima Trinidad.

La nueva cosmovisión resultante de la inculturación es una creación o reelaboración de la concepción tradicional del supramundo, en la que hay 13 Mesas sagradas en lugar de una. Los catequistas les han dado diferentes nombres: Mesa de la riqueza, corazón, de leche, de flores, de hojas, etc. Por otra parte, en el libro se han relacionado las diferentes Mesas con el calendario ritual mazateco. Cada mesa corresponde a tres meses del calendario ritual y cada periodo de tres meses, o una mesa, se celebra un rito relacionado con el trabajo de esa época o alguna festividad importante.

El plano inferior del cielo no se menciona en el libro de la Prelatura de Huautla, tal vez por no haberle encontrado "adecuación" con la cosmología cristiana, pero los chjota chjine dicen que, por debajo del arco, transita n'ai ch 'aon; el Padre trueno; representado por el relámpago-rayo, asociado con la lluvia y con la figura de una anciana de pechos grandes sentada sobre el mar, llamada Ch'iu majén, que amamanta las milpas y a quien le ofrecen un rito-fiesta llamado kjién-kjon, comida 
de la naturaleza, remarcando que todo lo que pertenece a kjon (de la naturaleza), es xkón, muy delicado, de alto riesgo. Boege (1988) y Doesburg y Carrera (op.cit.) registraron un mito sobre el Padre-Madre trueno-rayo que explica la práctica del ritual antes mencionado.

Tampoco menciona el libro a la dueña y cuidadora de la tierra, jchinga Sobé, "la vieja Elizabeth o Isabel", o najchá Sali, "la abuela Isabel", quien también es la dueña del fuego y del temazcal y la guardiana del mundo de los muertos. Ahora (p.27) se habla de la abuela y el abuelo, que sostienen el mundo desde su casa en la séptima mesa celeste. En la nueva cosmovisión los nombres de Dios, a quien se personifica como un anciano de barba blanca, son: Padre y Madre, nuestro Dueño, la Abuela (no hace referencia a la abuela que crió a sol y luna de unos huevos ni a la vieja Elizabeth), la Madre Tierra, el Padre sol.

b) En la cosmovisión tradicional la tierra, de planta cuadrada, está rodeada de agua y sostenida en las cuatro esquinas por los chikones, columnas del cosmos, que son las entidades sagradas territoriales conocidas genéricamente como Dueños del Cerro, a quienes la nueva espiritualidad llama "dueños del mundo", sin referirse a ellos con ningún detalle. En los espacios del monte y monte alto se localizan las montañas, ríos, ojos de agua y otras formaciones geográficas recorridas y protegidas por entidades territoriales sagradas llamadas chikones (kjon- xkon), al igual que las milpas y los caminos y veredas, que suelen ser riesgosos al ser transitados por los chikones, las chjoón chikon (dueñas, o mujeres del chikon) y los la'a, duendes. Chikones y la'a son capaces de atrapar y secuestrar los alter ego de personas que rondan sin protección por lugares peligrosos o sagrados, causándoles enfermedades o la muerte.

Van Doesburg y Carrera (1996) registran a los chikones como los ancianos antepasados, que se salvaron en los cerros cuando ocurrió el diluvio, y que posteriormente constituyeron el "Consejo de ancianos". Actualmente la palabra chikon es usada para denominar "lo sagrado, delicado, xkón, el que manda, güero, persona brillante, que intercede por su pueblo. Los chikones son parejas masculino- femenino, y cada lugar en el mundo tiene su dueño o chikón.

Un cambio de envergadura que ha promovido la cosmovisión inculturada es que sólo se ha conservado la faceta benéfica y protec- 
tora del chikón, no la predadora de almas. Los chikones, al igual que los chjota chjine, han perdido la característica mesomericana de la dualidad ética, personajes con poderes ambivalentes, de beneficio y de daño, de acuerdo con las circunstancias de la interacción humana o sagrado-humano, y en la religión inculturada sólo son benévolos, incapaces de daño. Así, se omite presentar la faceta predadora de los chikones, quienes al enfermar a la gente débil o de espíritu delicado se alimentan de su espíritu, o la faceta justiciera, cuando los chikones raptan el espíritu de la persona y la enferman y matan para castigar diversas infracciones al sistema normativo comunitario por parte de una persona.

Por otra parte la nueva cosmovisión adjudica a Dios el control del sol, la lluvia, el aire y los truenos, omitiendo a los chikones quienes son Dueños de estos elementos. Los chikones, sostenes del mundo, son asimilados a los santos, como auxiliares del Dios.

Los misioneros Josefinos, a través de los grupos o comunidades de base, han enfatizado el alto valor a los ojos de Dios, de los trabajos colectivos (tequios, mano vuelta, etc.) que los mazatecos realizan, como parte del amplio sistema de intercambios recíprocos, intentando celebrar los ritos de carácter colectivo junto con el trabajo. En tanto que inculcan la noción de trabajo como la obra de Dios, en la cosmovisión tradicional es el chikon Tokosho, Cerro de la adoración, quien enseña a sembrar a la gente (Borge, 1988, p. 104).

c) En la cosmovisión tradicional, por debajo de la superficie terrestre, se encuentra el inframundo, también concebido en dos niveles; el superior, conectando con el plano terrestre mediante cuevas, cavernas o sótanos a manera de "portales", es el sitio donde gobierna el chikon nanguí, Señor de la tierra. Este mundo es también visitado por los chojta chjine durante estados alternos de conciencia para comunicarse con los Dueños de los Lugares. En la parte inferior del inframundo, se concibe otro arco que inicia en el poniente y concluye en el oriente, formado por siete "peldaños" o lugares por donde peregrinan los muertos, que son sitios de sufrimiento donde se paga por los errores cometidos en vida; cuanto más faltas mayor dificultad para atravesarlos y mayor suplicio. A los cuarenta días del fallecimiento, después de levantarse la cruz, "el espíritu cabeza" de la persona inicia su camino pasando de 
uno a otro de los siete planos hasta arribar al mundo de los muertos. En cada piso se presenta un obstáculo: viento, arbustos con espinas, fuego, animales del maligno, el juicio por las acciones en la vida, cruce a la orilla del Gran Río o Mar Sagrado con la ayuda de un perro, y llegada a "la gloria", el do asean.

En la cosmovisión inculturada poco se habla del inframundo (los entrevistados dicen que no se trató mucho el tema en las reuniones), pero la concepción es muy diferente a la mazateca. Se escribe sobre un medio arco debajo de la superficie, con cinco pisos o capas de agua, bajo el control de la Madre Tierra. El mal (p.33) es equiparado con fuerzas que se oponen a Dios; el chato es un personaje maligno a quien se acude por riquezas y roba el alma y hace siervos a la familia. El chato es la contraparte del chikón.

La "nueva espiritualidad mazateca", como le llaman los misioneros a esta cosmovisión construida, ignora el camino lleno de obstáculos hasta alcanzar el mundo de los muertos, y dice que en el camino el difunto atraviesa primero cuatro cruces como puertas y si pasa se le perdonan los pecados. Luego cruza otras tres puertas y la séptima es la entrada a la Vida. De esta forma alteran las concepciones sobre el mundo de los muertos y el camino de obstáculos que el alma debe pasar para llegar a él.

d) A los chjota chjine (chamanes), ahora llamados sabios o guías, se les da una función sacerdotal, como mediadores entre Dios y el pueblo, y se minusvalora su papel como mediadores entre la gente y los chikones, que son primordiales.

El chjota chjine, como consecuencia de su nuevo papel sacerdotal y exclusivamente benévolo (terapéutico), ha perdido también la dualidad ética, y esto ha producido un desdoblamiento de especialistas rituales. Los que se dedican al bien son los nombrados como chjota chjine, sabios, y los que se dedican al mal, la brujería, son los tje'e o brujos. Estos últimos son generalmente clandestinos, nadie admite tener relación con ellos y son condenados por la iglesia.

e) En el libro se mencionan dos relatos relacionados con la creación de bienes culturales (el maíz y el fuego por el tlacuache que se los quita a la Abuela), pero la mitología tradicional que narra como el 
rayo, el trueno, el arco iris, diferentes animales, la esposa del chikón Tokosho, la Chumaje dueña del agua de abajo de la tierra y dueña del rayo, $\mathrm{u}$ otros personajes, entregan bienes preciados a los hombres para que sobrevivan en la tierra, ha sido omitida. Junto con la narrativa se suprime a estos personajes de los ritos propiciatorios y de agradecimiento, y en los pueblos actuales los ritos cambian o se suprimen, y se suplica sólo a Dios por una buena temporada de lluvias, una buena cosecha o buena salud.

No se mencionan ni el mito del origen del mundo ni el de los Gemelos Sol y Luna. Respecto de este mito, que hoy ya no se escucha mucho, Boege (1988:95) recogió en la década de 1980 una versión que mezcla el clásico episodio de la anciana que encuentra dos huevos que más tarde son dos niños y después Sol y Luna, con elementos católicos cuando los niños son Jesucristo y el Padre Eterno que venían en busca de la luz que guardaba la anciana, ya que hasta entonces el mundo era oscuro, reinaba el chikón nangui y la Santísima Trinidad dio la luz a la humanidad. Ya para entonces los mazatecos incluían personajes católicos en la versión de este mito, a diferencia de otros grupos de Oaxaca.

Hay dos nuevos mitos en el libro, el de la creación del hombre y de la mujer (p.49), creados por Dios cuando el universo era un lago. Dios le tira hierba al agua y salen los animales, le tira maíz a otro y éste se hace hombre. Después del diluvio universal crea a la mujer convirtiendo a un perro en ella. Esto es, que los catequistas crearon mitos inexistentes en la tradición cultural mazateca.

f) En la cosmovisión tradicional, entre las entidades anímicas que integran la persona humana, el "espíritu cabeza" sólo abandona el cuerpo después de la muerte, y el xhimajo, segundo o tona, tiene la capacidad de salir temporalmente del cuerpo durante ciertos momentos; en los sueños, durante las "veladas" con ingestión de enteógenos, y cuando se pierde la conciencia a causa de alguna enfermedad o accidente graves. En estos casos se corre el riesgo de que la entidad anímica se pierda o sea atrapada por alguna entidad territorial, lo que pone en riesgo la salud y hasta la vida. El espíritu principal o "cabeza", sén nizh'gin o sén nizjin, es la fuerza vital del cuerpo, radica en la cabeza 
o el corazón, pero por un susto o espanto puede cambiar su ubicación y circular por las venas junto con la sangre, por eso los curanderos buscan su posición, fuerza y temperatura en las coyunturas del brazo con antebrazo y en las venas del interior de la muñeca, lugares que son frotados con piciete, sangre, agua de cacao y otros elementos terapéuticos durante los rituales de curación. Esta entidad anímica no sale del cuerpo durante la vida, pero sí después de la muerte y de manera definitiva, por la boca, en forma de aire o soplo, convive por un tiempo con amigos y familiares, deambula por los sitios recorridos en vida y finalmente, después de la "levantada de la cruz", inicia su camino al inframundo de donde retorna cada año durante la semana de "Todos Santos". Está asociada con el aire, el calor y la sangre, elementos presentes en los rituales de curación practicados a enfermos débiles a fin de incrementar su fortaleza.

El xhimajo, segundo o tona, se concibe como la entidad anímica que permite el crecimiento del niño, y es vulnerable fuera del cuerpo. En Ayautla se le conoce como xhimajo, xhimajone o xhimajoni, el segundo, él que sigue o segundero", y en toda la mazateca es referido en castellano como: doble, reflejo, espejo, imagen, o segundo. Existe la idea que las personas tienen varias tonas en forma de animales silvestres de diferentes tamaños e importancia, también pueden tener forma de astros, fenómenos atmosféricos y de seres humanos. Estas entidades anímicas se enumeran como: el segundo, tercero, cuarto, quinto y demás, y a lo largo de la vida pueden ir muriendo, causando malestares de cierta importancia según el orden de la tona afectada. Aquellas que sobreviven a la muerte del espíritu principal, se integran a él y comparten su destino.

En la nueva cosmovisión las tonas o alter ego animal o fenómeno atmosférico de las personas están por completo ausentes. Se pierde la concepción de tener un animal compañero con quien se comparte el espíritu (de hecho ya no se buscan las señales de las tonas al momento del nacimiento), de que el espíritu compañero o doble puede ser atrapado por los chikones o los brujos tanto en sueños como en la vida ordinaria durante un susto. Pierden sentido los rituales de recuperación de la tona. Ahora es el espíritu el que se enferma y es simplemente por acciones del diablo. También han sido eliminados 
los naguales, que son las transformaciones animales o fenómenos atmosféricos que experimentan los chjota chjine (buenos y malos) y algunas otras personas mediante la manipulación de sus tonas. En la práctica etnográfica contemporánea es difícil encontrar chjota chjine que reconozcan la existencia de tonas y naguales.

En términos de la cosmovisión las concepciones mazatecas han sido transformadas amplia y profundamente, mediante la reelaboración de mitos y creencias, la selección u omisión de determinados conceptos o elementos religiosos, y la creación de un sincretismo entre Dios y otros personajes sagrados del panteón mazateco.

\section{Algunas Transformaciones Inducidas en la Ritualidad}

a) El libro Elementos rituales mazatecos y la observación etnográfica permiten señalar la adopción arbitraria de fragmentos de rituales del ciclo vital mazateco en la nueva liturgia de la misa y los sacramentos del bautismo, el casamiento y los funerales. En los nuevos ritos en general se mantienen los elementos de la ofrenda y las etapas de los ritos mazatecos pero se enmarcan en oraciones, cantos e ideas católicas que aluden a Dios Padre y a la limpieza del pecado. El chjota chine nombra a Dios en la nueva liturgia y mucho menos a los chikones. A los elementos rituales mazatecos se agregan la ostia y el agua bendita y se imponen las flores blancas por sobre las de otros colores.

Las poderosas entidades territoriales fundadoras del cosmos y reguladoras de la vida, parecen no adecuarse muy bien al Evangelio, por lo cual en el libro se habla poco de ellas y tanto en los relatos como en los rituales muchas veces aparecen reemplazadas por Dios.

b) Como sacramentos se proponen: bautismo, consagración, reconciliación o purificación comunitaria, ritos para enfermos, ritos para moribundos y ritos para difuntos. Es decir que se agregan dos sacramentos; de reconciliación comunitaria y para los enfermos; ritos que no tenían antecedentes entre los mazatecos.

Para el bautismo, en la iglesia, el libro dice explícitamente que “[...] fusionan el rito mazateco con el católico [...]" (p. 72). Así, han incorporado el rito de reverdecimiento o retoño, mediante el cual el niño es reconocido por Dios y los “dueños del mundo". Este rito antes 
se hacía en la casa del niño con los padrinos y el chjota chjine, como protección para la infancia, no para el bautismo. Para el bautismo tradicional el chjota chine hace una limpia en la que frota al niño en las partes mencionadas del cuerpo con piciete y agua de cacao y pasa sobre el los envoltorios sagrados que más tarde serán enterrados. El nuevo rito incluye un baño ritual del niño para quitarle el pecado antes de pasar a la Mesa para el reverdecer. Después viene el lavado de manos del niño, sus padres y los padrinos. Después van a la Mesa sagrada y le imponen el nombre y realizan el rito de reverdecer, untándole al niño con 13 gotas de la sangre del ala del guajolote con cacao y agua. Luego se le ofrecen al niño la vela encendida, una mata de árbol, un guajolote vivo y una flor blanca, sucesivamente. Se unta al niño con piciete como protección, y se lee la Biblia. En este rito novedoso ni se mencionan los envoltorios sagrados de ofrenda al chikon nangui que se siembran fuera de la casa. El reverdecimiento o fortalecimiento como purificación se usa en otros ritos nuevos como el de reconciliación comunitaria, siempre mezclado con cantos y oraciones católicas.

Asimismo, han llevado a la boda eclesiástica el "lavado de cabeza" de la novia, que es parte medular del rito tradicional de alianza matrimonial que se realiza en los espacios domésticos de los contrayentes.

c) Otro nuevo ritual es la peregrinación de pedido de lluvia acompañada por el sacerdote que bendice el lugar y oficia misa en el cerro sagrado, eliminando los otros ritos adivinatorios con sangre de ave que los especialistas acostumbraban a realizar durante esos rituales.

Igualmente han eliminado la muerte de la guajolota o el gallo en los ritos de curación de espanto, que era la ofrenda para el chikón nanguí para que soltara el espíritu del enfermo (Inchaustegui, 1977, p. 139). Actualmente, las aves se les dejan vivas al chikón. La sangre del ave se utiliza sólo como gotas y mezclada con agua y cacao, ya sea para untar o soplar sobre el paciente.

En ritos de petición y agradecimiento por el terreno sembrado o por la vivienda se entierra un gallo o guajolote vivo por 4 días, pero no mueren. Han eliminado los ritos de muerte del animal. Esos animales de los ritos deben morir de muerte natural.

d) El uso frecuente de hongos psicotrópicos en contextos rituales no era una tradición fácil de asimilar por la iglesia. La nueva liturgia 
promueve un modelo de 'velada' de hongos en el que se sobrevalora la presencia de Dios y se menciona muy poco a los chikones y los chala'a, con quienes originalmente se comunica el chjota chjine en los cuatro rumbos del cosmos. Se habla de los hongos como mensajeros de Dios y del chjota chine como el sabio guía que orienta el viaje hacia Dios (p.27). La nueva 'velada' tiene las siguientes etapas: Entrada hacia el camino de Dios; Obstáculos, como serpientes, gusanos o malos espíritus que Dios pone en el camino del pecador como prueba. Se pasa con la oración; Prueba, aparece un guía, y una luz que es el Espíritu de Dios. El sabio debe luchar para ir por el bien y no por el mal que se presenta como muertos; Iluminación es el viaje lleno de alegría, el espíritu de Dios se posesiona de la persona. Si no se ha superado bien la etapa anterior en ésta Dios regaña al pecador; Consejos, el Espíritu de Dios muestra las causas de las enfermedades al sabio respaldado por los santos y los chikones, que en lenguaje sagrado le habla a Dios; Despedida y Agradecimiento, Dios regresa el espíritu de la persona a su lugar, lo trae de los lugares lejanos por donde ha viajado, todos los participantes del ritual guardan dieta de 4 días y están atentos a los sueños en los que Dios anuncia el resultado del rito. Dios ha reemplazado a los chikones, aunque los cuatro rumbos y los cuatro días de dieta se refieren a ellos. De los hongos se dice que son el cuerpo de Dios y la manera de comunicarse con él, se omite que son considerados entes sagrados en sí mismos, no intermediarios y que uno de sus usos es la revelación del poder chamánico.

e) Los elementos de la ofrenda tradicional a los chikones, que componen los envoltorios sagrados o paquetes de pedimento que se entierran después de la velada, son: granos de cacao, papel de amate o estraza, pluma de guacamaya o de pato, tabaco piciete, huevos de guajolota o de gallina. Todas las ofrendas contienen los mismos elementos, lo que varía es la cantidad, pedida al sabio por los chikones. El libro menciona la ofrenda para los "dueños del mundo" (en mazateco dicen chikón Nindó, dueño del cerro) pero no dicen que son envoltorios que se entierran.

El copal es un elemento purificador y protector que se utiliza para limpiar el espacio del rito y propiciar a las presencias numinosas (benéficas pero peligrosas), como los Dueños del Lugar; por ello se 
ahúma hacia las cuatro esquinas y el centro; los rumbos del cosmos. En la nueva liturgia se ahúma con copal al iniciar la misa para "preparar el camino para ser escuchados por Dios".

En la nueva liturgia se ha adoptado una mezcla de tabaco piciete (protector), agua de cacao y gotas de sangre de bajo el ala del guajolote u otra ave, para los ritos de purificación previos a los bautismos, las bodas, las curaciones, la protección de las milpas y las viviendas. Pero no se pone en los lugares adecuados y se omiten señalar que este líquido se unta en cabeza, pecho y coyunturas porque es en esos sitios donde se alojan los espíritus cabeza y las tonas, que recorren el cuerpo llevados por la sangre.

De las plumas de guacamaya para los paquetes de ofrenda para los chikones, mencionan las rojas que son para curar pero no las azules que son para pedir daños.

Igualmente cuando dicen que la mesa ritual no debe ser tocada por cuatro días (cuidados posteriores a los ritos) no hacen referencia a que ese cuidado es porque están cargadas del poder de las entidades sagradas de los cuatro rumbos del universo, que estuvieron presentes en el rito.

Toda la nueva liturgia para diferentes rogativas y pedimentos se desarrolla en el espacio del templo en horario diurno (de la madrugada al mediodía), el tiempo de la luz y lo bueno en el que Dios Padre (el sol) comienza su recorrido, y el horario vespertino, cuando acaba su recorrido, es para dar gracias. Con ello dejan fuera de tiempo apropiado a las 'veladas' con hongos psicotrópicos, el ritual adivinatorio y terapéutico más importante de los mazatecos, que comienzan en la noche y terminan en la madrugada.

\section{Conclusiones}

Desde mi perspectiva la intervención actual de la iglesia católica en la cultura y la religión que los indígenas practican constituye un nuevo acto de evangelización etnocida. Se trata de un proceso de aculturación dirigida en el que se inducen los diversos sincretismos. Los cambios en la cosmología y las prácticas rituales no surgen de los 
mazatecos por decisión propia, no son reelaboraciones y reconfiguraciones colectivas producidas dentro de la dinámica de la cultura nativa sino que ésta resulta transformada desde el catolicismo a través de los catequistas adoctrinados en la Teología India.

La "iglesia autóctona" que los misioneros esperan construir está sustentada en la práctica de la inculturación, y la "nueva espiritualidad mazateca", como le llaman a esa creación religiosa seleccionada, es el resultado de la exclusión de aspectos centrales de la cosmovisión y la ritualidad indígenas, de la reelaboración de otros aspectos considerados más compatibles con el catolicismo, y de la implantación de nuevos conceptos teológicos, nuevos sacramentos y nueva liturgia. Una diferencia principal entre las "iglesias autóctonas" y las "iglesias nativas" (Barabas, 2002), es que las primeras resultan de procesos incitados o promovidos por los catequistas de la nueva corriente teológica, en tanto que las segundas son creaciones culturales propias de los indígenas, que devienen de movimientos sociorreligiosos y de procesos colectivos de selección y apropiación cultural.

La discriminación hacia las creencias y rituales nativos y los intentos activos de cambiarlas para "civilizarlas"; esto es, hacerlas compatibles con el catolicismo, son formas de racismo contemporáneo que con máscara de respeto e interculturalidad se proyecta sobre los indígenas para volverlos a catolizar.

\section{Notas}

1 El autor realiza una combinación de opciones entre la cultura propia, la cultura apropiada, la cultura impuesta y la cultura enajenada, a partir del eje del control cultural.

2 Esta panorámica de la historia de la Teología India entre los mazatecos es producto de las conversaciones sostenidas entre la antropóloga Lidia Manrique, quien gentilmente me ha proporcionado el texto de las entrevistas, y los misioneros Josefinos José Luis Sánchez (no mazateco, sacerdote) y Heriberto Prado (mazateco, no ordenado), encargados, junto con otros, de la pastoral indígena en la región. En los párrafos que siguen los entrecomillados reproducen palabras textuales de los entrevistados. 


\section{Referencias}

BARABAS, Alicia. La construcción del indio como bárbaro. De la etnografía al indigenismo. Revista Alteridades, México, v. 19, UAM Iztapalapa, 2000.

Utopías Indias: movimientos sociorreligiosos en México. 3. ed. México: Plaza y Valdés - INAH, 2002.

. El racismo en la práctica de la Teología India. Summer Scholl of Religions, San Giminniano, Itália, August, 2009.

BERLIN, Henrich. Idolatría y superstición entre los indios de Oaxaca. México: Toledo, 1988.

BOEGE, Eckart. Los Mazatecos Ante la Nación. México: Siglo XXI, 1988.

BONFIL BATALLA, Guillermo. Lo propio y lo ajeno: una aproximación al problema del control cultural. La Cuestión Etnica en América Latina. (Coord. Barabas y Bartolomé). Rev. Mexicana de Ciencias Políticas y Sociales, v. 103, México, UNAM, 1981.

BOTASSO, Juan (comp.). Iglesia, Pueblos y Culturas. 1. ed. Quito: Abya Yala, 1986.

COLAJANNI, Antonio. La actividad misionera Salesiana entre los Shuar de Ecuador. En nombre de Dios: la empresa misionera frente a la alteridad. (Coord. F.) Quito: Cuturi, Abya Yala, 2008.

CUTURI, Flavia. Introducción: adaptarse, modelar y convertir. En nombre de Dios: la empresa misionera frente a la alteridad. (Coord. F. Cuturi). Quito: Abya Yala, 2008.

DE LA FUENTE, Julio. Las ceremonias de la lluvia entre los zapotecos de hoy. Actas del XXVIII C.I.A. México: UNAM, 1939.

DOESBURG, Geert Bastiaan van; CARRERA GONZALEZ, Florencio. Chan-Chaon-Yoma, el calendario agrícola mazateco. Sexta parte, Códice Ixtlixochitl. México: CIESAS-Istmo, A DV-Austria y FCE, 1996.

GILLOW, Eulogio. Apuntes históricos sobre la idolatría y la introducción del cristianismo en la Diócesis de Oaxaca, Akademische Druck-U-Verlag Sanstalt Graz-Austria, 1978

GNERRE, Maurizio. Misioneros frente al desafío de la alteridad comunicativa. En nombre de Dios: la empresa misionera frente a la alteridad. (Coord. F. Cuturi). Quito: Abya Yala, 2008.

InCHAUStegui, Carlos. Relatos del Mundo Mágico Mazateco, INAH, México, 1977. 
. Grupos étnicos en México. México: Instituto Nacional Indigenista, SEP, 1982. (2 vols.)

. La Mesa de Plata: cosmogonía y curanderismo entre los mazatecos de Oaxaca. Oaxaca: IOC, 1994.

MANRIQUE, Lidia. Rituales de pasaje en tres comunidades

mazatecas. Tesis de licenciatura en etnología. México: ENAH, 2004.

Cosmovisión y geografía sagrada mazateca. México:

Cosmovisión y Mitología en México, 2008. (en prensa)

MARZAL, Manuel. Los caminos Religiosos de los inmigrantes de la gran Lima. Pontificia Universidad Católica del Perú, Fondo Editorial. Peru: CONCYTEC, 1989.

PRELATURA DE HUAUTLA. Elementos Rituales Mazatecos. Escuela de Ministerios, Huautla de Jiménez, Oaxaca, México,1998.

RUIZ, Samuel. En esta hora de gracia: carta pastoral.México: Dabar, 1993.

SEPULVEDA, María Teresa. Proceso por idolatría al cacique, gobernadores y sacerdotes de Yanhuitlán, 1544-1546. México: Col. Científica 396, INAH, 1999.

Recebido em 20/06/15

Aceito em 22/08/15 